\title{
PANORAMA DES PRINCIPAUX DANGERS BIOLOGIQUES ET ASSIMILÉS D'ORIGINE ALIMENTAIRE
}

\author{
MOST IMPORTANT HAZARDS FROM FOOD: AN OVERVIEW
}

Par Alain GUIGNARD ${ }^{1}$

(Communication orale présentée le 27 mai 2021, manuscrit accepté le 4 octobre 2021)

\begin{abstract}
RÉSUMÉ
L'article dresse un panorama actualisé des principaux dangers d'origine alimentaire. L'accent est mis sur les dangers d'origine bactérienne, au regard de leur importance soulignée par les données de surveillance relatives aux toxi-infections alimentaires collectives. II propose une représentation schématique des composants de la flore mésophile, ainsi qu'un guide d'interprétation des résultats d'analyses microbiologiques dans le cadre des autocontrôles et des TIAC. Les autres dangers sont présentés : histamine, virus, champignons et leurs toxines, parasites, phycotoxines et biotoxines marines, ESB, allergènes d'origine alimentaire, contaminants chimiques, agents responsables de syndromes collectifs inexpliqués. L'auteur illustre sa présentation par des témoignages issus de son expérience de terrain.
\end{abstract}

Mots-clés : toxi-infection alimentaires collectives, sécurité sanitaire des aliments, contaminants microbiologiques et chimiques

\begin{abstract}
-ABSTRACT
The article provides an updated overview of the main food-borne hazards. The emphasis is on the hazards of bacterial origin, considering their importance underlined by the monitoring data issued from food-borne outbreaks. A schematic representation of the components of the mesophilic flora is provided as an interpretation guide for the results of microbiological analyzes in the context of self-checks and food poisoning outbreaks. The other contaminants are presented: histamine, viruses, fungi and their toxins, parasites, phycotoxins and marine biotoxins, prions, food allergens, chemicals, agents causing unexplained collective syndromes. The author illustrates his presentation with personal comments based on his field experience.

Key-Words: food poisoning outbreak, food safety, microbiological and chemical contaminants
\end{abstract}

\section{INTRODUCTION}

Cet article vise à mettre un outil au service des différents acteurs de la santé publique. Il s'inscrit dans la démarche "One world-One health " (Angot JL, 2020) en démontrant que le décloisonnement sectoriel humain-animal-aliment-environnement doit se poursuivre. Quel que soit le contexte, industrie agro-alimentaire, restauration collective ou hygiène domestique, le respect des bonnes pratiques permet de garantir la qualité sanitaire des productions alimentaires : pratiques de travail satisfaisantes, respect de l'hygiène et de la propreté, lavage des végétaux, respect de la chaîne du froid, refroidissement rapide, durée de conservation courte, etc.
Malgré les précautions engagées, les aliments sont régulièrement à l'origine de désordres sanitaires affectant la santé humaine. Les manifestions cliniques observées sont en général liées à la présence indésirable de microbes pathogènes, en plus ou moins grande quantité, ou au produit de leur métabolisme. D'autres éléments peuvent être en cause, tels que prions, substances toxiques, polluants environnementaux... L'étymologie du mot microbe provient du grec ancien $\mu$ IKpóc, mikros «petit » et ßíoc, bios «vie», ce qui signifie « être vivant invisible à l'œil nu " et révélé au microscope (optique ou électronique).

Le monde des microbes recouvre essentiellement virus, bactéries, champignons, levures et parasites.

1 - Inspecteur général de santé publique vétérinaire de classe normale, Ministère de l'Agriculture, ancien directeur du laboratoire national vétérinaire de Rungis de 1994

à 2007, 2 rue des Terres au Curé 75013 Paris. Courriel : alain.guignard55@orange.fr 
Ce document présente une synthèse des principaux dangers d'origine alimentaire rencontrés ou susceptibles de l'être, complétés par quelques témoignages représentatifs, certains fruits des observations de 25 ans de pratique de terrain en laboratoire de routine.

Il comporte aussi un tableau synoptique permettant :

- d'établir rapidement un diagnostic différentiel des TIAC les plus fréquentes, à partir des observations obtenues ;

- d'orienter plus facilement la reconnaissance des aliments en cause ;

- de mieux comprendre le sens des résultats des analyses de laboratoire.

Les dangers les plus fréquemment rencontrés en pratique courante sont liés à certaines bactéries : salmonelles, staphylocoques, Clostridium, Bacillus cereus, Campylobacter, Listeria, histamine, norovirus, etc. Ils sont facilement identifiés et les soins maitrisés. Néanmoins, il nous a paru important d'établir un panorama de tous les autres dangers recensés. Moins fréquents, moins souvent suspectés, parfois méconnus, leur impact est de ce fait sous-évalué. Certains d'entre eux constituent des maladies émergentes, susceptibles d'induire des situations sévères. Sauf quelques exceptions, les dangers liés aux caractéristiques intrinsèques des boissons et des produits végétaux ne sont pas abordés.

\section{LES TOXI-INFECTIONS ALIMENTAIRES COLLECTIVES (TIAC) ET AUTRES TROUBLES D'ORIGINE BACTRIOLOGIQUE}

(Santé publique France, surveillance des toxi-infections alimentaires, 2019)

\section{Définition}

Une TIAC est définie par l'apparition d'au moins 2 cas d'une symptomatologie similaire, en général gastro-intestinale, dont on peut rapporter la cause à une même origine alimentaire. En France, les TIAC sont à déclaration obligatoire (DO) depuis 1987.

\section{Déclaration}

La déclaration d'une TIAC auprès de l'administration (agence régionale de santé (ARS) et/ou direction départementale (de la cohésion sociale) de la protection des populations (DD(CS)PP) est obligatoire pour les médecins et les responsables d'établissements de restauration collective ou à caractère social. La déclaration peut également être faite par des consommateurs qui ont connaissance d'un épisode pouvant être une TIAC. Cette déclaration entraîne des investigations conjointes pour tenter de déterminer l'origine de la TIAC.

La coordination des TIAC et situations sanitaires d'urgence est coordonnée par les représentants sanitaires institutionnels de la santé humaine, principalement : Santé Publique France $(\mathrm{SpF})$, Direction Générale de la Santé (DGS), Direction Générale de l'Alimentation (DGAL). Elles font également intervenir de nombreux autres acteurs : laboratoires, industriels, responsables qualité, diététiciens, médecins scolaires, etc.

\section{Données de 2019}

1783 toxi-infections alimentaires collectives (TIAC) ont été déclarées en France, affectant 15641 personnes, dont 609 (4\%) se sont présentées à l'hôpital (hospitalisation ou passage aux urgences) et 12 sont décédées. Les chiffres de 2020 ne sont pas encore publiés. Le nombre de déclarations augmente régulièrement depuis 1987. Ce qui est probablement dû à un perfectionnement des conditions de déclaration, la mise en place de l'outil Wintiac, l'amélioration des méthodes de détection des micro-organismes... Comme lors des années antérieures à 2019, l'agent pathogène le plus fréquemment confirmé était Salmonella pour $35 \%$ des TIAC pour lesquelles un agent a été confirmé : presqu'une 1 fois sur 3 ! Les autres agents pathogènes en cause, les plus couramment confirmés, ou suspectés sur la base des informations épidémiologiques et cliniques, étaient les agents suivants : Staphylococcus aureus, Clostridium perfringens, Bacillus cereus et Campylobacter.

Dans 16\% des TIAC déclarées, aucun agent n'a pu être mis en évidence, ou suspecté sur la base des informations épidémiologiques et cliniques fournies. Ces proportions demeurent assez semblables d'une année à l'autre.

\section{Commentaires}

Ces données constituent des tendances, car elles sont entachées de biais. Elles représentent le fruit de l'étude synthétique des données transmises par les services officiels. Toutes les TIAC ne sont pas déclarées aux autorités, les cas graves ou spectaculaires sont plus facilement déclarés car ils échappent peu à la vigilance des responsables. Parfois, il y a rétention d'information, par craintes de représailles, de médiatisation, d'atteinte à la réputation, etc. Dans d'autres cas, certaines TIAC ne sont pas identifiées comme telles, lorsque les malades sont trop dispersés dans l'espace ou dans le temps, a fortiori lorsque les manifestations cliniques sont modérées ou fugaces, dans le cadre des TIAC familiales notamment. Les investigations conduites ne permettent pas toujours d'identifier la cause : absence de plats témoins (la réglementation impose de les conserver 5 jours, conformément à l'arrêté du 8.10.2013, alors que les délais d'intervention des services sanitaires peuvent prendre plus de temps, lorsque l'on additionne durée d'incubation, délai de latence du signalement, déclarations tardives, temps de réaction des services, week-end...), quantité insuffisante, mauvaises conditions de conservation (effet d'une congélation éventuelle), observations contradictoires, recherches inappropriées, etc.

Au-delà des TIAC proprement dites, les résultats d'une étude réalisée en France, portant sur la période 2008-2013, indiquent que la morbi-mortalité attribuable aux maladies infectieuses d'origine alimentaire reste élevée, avec 1,28 à 2,23 millions de cas annuels, dont 15800 à 21200 hospitalisations et entre 232 et 358 décès. En France, les infections à norovirus, Campylobacter spp. et Salmonella spp. représentent la majorité des cas et des hospitalisations d'origine alimentaire. Les infections à Salmonella spp. et Listeria monocytogenes représentent la moitié des décès d'origine alimentaire (Van Cauteren D. et al. 2018). 


\section{Les salmonelles : première cause de TIAC en France}

(https://www.anses.fr/fr/content/fiche-de-description-de-da nger-biologique-transmissible-par-les-aliments-salmone lla-spp-juin)

\section{Caractéristiques bactériennes}

Ce sont des entérobactéries, Gram -, non sporulées, anaérobies facultatives. La température optimale de croissance est de $35 / 37^{\circ} \mathrm{C}$. Il existe plus de 2600 sérovars, certains sont strictement adaptés à l'Homme (S. typhi, S. paratyphi A et B), d'autres aux animaux, d'autres aux deux (S. enteritidis, S. typhimurium).

\section{Sources}

L'environnement contaminé, y compris les végétaux, par les matières fécales des malades et des porteurs sains humains ou animaux, représente une source majeure de contamination. Poules, œufs, ovoproduits, viandes et produits à base de viande sont souvent incriminés, ainsi que les contaminations croisées, et une mauvaise hygiène des stocks.

\section{Manifestations cliniques}

Après 8 à 72 h d'incubation, une gastro-entérite grave fortement fébrile apparaît, avec prédominance d'une diarrhée profuse, associée à des vomissements et des myalgies.

La salmonellose peut entrainer des septicémies chez les personnes immunodéprimées, des manifestations chroniques (arthrites...), et une mortalité faisant suite à une déshydratation. La convalescence est longue.

Le portage reste fréquent après guérison, surtout après une antibiothérapie.

\section{Prévention}

Elle consiste à respecter des mesures d'hygiène générale, éviter les contaminations fécales directes ou indirectes. La recherche les témoins des contaminations fécales dans les aliments constitue une aide précieuse pour compléter le dispositif.

\section{Illustration}

En France, en 2005, une épidémie de salmonellose à S. agona, attribuée à la consommation de lait en poudre contamine plus de 140 nourrissons. En 2017, une nouvelle épidémie de salmonellose à S. agona atteint 38 nourrissons, des dizaines de millions de boîtes de produits infantiles commercialisés dans des dizaines de milliers de points de vente en France et dans plus de 85 pays sont rappelées (Bilan commun Salmonella et lait infantile : un concentré de données. François-Xavier Weill, centre national de référence salmonelle, Institut Pasteur - Nathalie Jourdan-Da Silva, direction des maladies infectieuses, Santé publique France. 2018. Non publié.)

\section{Staphylococcus aureus ou staphylocoques à coagulase positive}

(https://www.anses.fr/fr/content/fiche-de-description-de-da nger-biologique-transmissible-par-les-aliments-staphylococcus-0)

Caractéristiques bactériennes

Les S. aureus sont susceptibles de produire des entérotoxines thermorésistantes, beaucoup plus thermorésistantes que les formes végétatives. Ces entérotoxines sont à l'origine de TIAC par intoxination. Dans certains cas, des manifestions cliniques sont observées en l'absence de staphylocoques, si le produit a été soumis à un traitement thermique, rendant les investigations difficiles.

Sources

Les staphylocoques sont des bactéries ubiquitaires présentes sur la peau, les muqueuses et la sphère rhinopharyngée chez les animaux à sang chaud et en particulier chez l'Homme. La voie de contamination principale de l'aliment est majoritairement humaine, sauf pour les fromages où l'origine animale s'avère plus fréquente. La peau et les muqueuses de l'Homme (et des animaux) constituent l'habitat de S.aureus. Ces bactéries sont également isolées de l'environnement naturel (sol, eau douce et eau de mer, poussière, air), de l'environnement domestique de l'Homme (cuisine, réfrigérateur) et des ateliers de préparation alimentaire.

Aliments laitiers crus, produits manipulés, notamment crèmes pâtissières, mayonnaise, constituent des sources de prédilection.

\section{Manifestations cliniques}

La durée d'incubation et la sévérité des symptômes dépendront de la quantité d'entérotoxines ingérées et des sensibilités de chaque individu. Les manifestions cliniques occasionnées par les entérotoxines de $\mathrm{S}$. aureus sont proches de celles provoquées par la toxine émétique (céréulide) produite par Bacillus cereus. La durée de l'incubation est courte (entérotoxines préformées dans l'aliment agissant sur l'estomac), 2 à 4 heures, parfois moins. Quelquefois surnommée la "maladie des banquets ". Les manifestions cliniques sont passagères et dominées par des vomissements incoercibles. Après 1 à 8 heures, le rétablissement est généralement complet.

\section{Prévention}

La prévention repose sur le respect de l'hygiène générale, sur l'éviction des porteurs présentant des lésions ou des symptômes de type rhino-pharyngé. Le respect de la chaîne du froid et refroidissement rapide sont capital pour éviter la multiplication des staphylocoques et in fine la production de toxines.

\section{Témoignage}

A l'île de la Réunion, fin des années 80 , une préparation de gâteaux à la crème pâtissière en vue d'offrir une friandise aux enfants, fin décembre, le dernier jour d'école avant le départ en congés de fin d'année, avait été faite. L'entreprise était défaillante : pas de réfrigérateur, début des préparatifs culinaires 3 semaines avant le jour de distribution, transport des gâteaux le matin, à température ambiante (décembre est un des mois les plus chauds de l'année, sous les tropiques). La consommation commencée le samedi vers midi, conduit une heure plus tard, à une « épidémie " de vomissements affectant près de 2000 enfants.

\section{Clostridium perfringens (anaérobies sulfito- reducteurs)}

(https://www.anses.fr/fr/content/fiche-de-description-de-da nger-biologique-transmissible-par-les-aliments-clostridium-1) 
Caractéristiques bactériennes

Ce sont des bacilles Gram +, sporulés (spore détruite $1 \mathrm{~h}$ à $100^{\circ} \mathrm{C}$ ), anaérobies, mésophiles, dont la température optimale de croissance est inférieure à $52^{\circ} \mathrm{C}$. C. perfringens produit une entérotoxine, libérée au cours de la sporulation, dans le gros intestin, en fin de digestion.

\section{Sources}

Les principales sources sont représentées par les matières fécales et les contaminations telluriques, notamment lors de l'emploi de légumes insuffisamment lavés.

\section{Manifestations cliniques}

Après une incubation de 6 à $12 \mathrm{~h}$ (donc en fin de digestion), apparaît une gastro-entérite avec prédominance de diarrhées et douleurs abdominales, sans fièvre, surnommée "diarrhée de minuit". Le rétablissement est rapide, en quelques heures.

\section{Prévention}

La prévention repose sur le respect des règles élémentaires d'hygiène générale, une réfrigération rapide (passage à une température inférieure à $10^{\circ} \mathrm{C}$ en moins de 2 heures) ou le maintien en liaison chaude (température $63^{\circ} \mathrm{C}$ ).

\section{Témoignage}

Un cuisinier, dans un internat d'enfants, avait commencé la cuisson d'une énorme marmite de haricots des jardins, secs, la veille, suivie d'un arrêt de la cuisson, la nuit, sans refroidissement, suivie d'un réchauffement lent le matin avant consommation. Résultats : une trentaine de malades au milieu de la nuit, tous guéris au petit matin.

\section{Bacillus cereus}

(https://www.anses.fr/fr/content/fiche-de-description-de-danger-biologique-transmissible-par-les-aliments-bacillus-cereus-0) (Guignard \& Renaud, 2018)

\section{Caractéristiques bactériennes}

Les bactéries appartenant au genre bactérien Bacillus ont la capacité de sporuler et ainsi de résister sous forme de spores à des conditions défavorables de température ou de déshydratation. Les Bacillus nommés Bacillus cereus, produisent des toxines à l'origine de TIAC.

\section{Sources}

Les B. cereus sont abondants dans les sols et peuvent particulièrement contaminer les végétaux (tubercules, légumes, épices, etc.). "Sans être limitatifs, les plats cuisinés, les produits agrémentés d'épices, d'herbes ou d'aromates, les aliments déshydratés reconstitués par addition d'eau chaude conservés à une température permettant la croissance de Bacillus cereus (températures comprises entre $4^{\circ} \mathrm{C}$ et $55^{\circ} \mathrm{C}$ ), et avec une consommation différée, figurent parmi les aliments à risque, au regard du danger Bacillus cereus ".

\section{Manifestations cliniques}

B. cereus peut produire deux types de toxines. Les toxines qui provoquent des symptômes de type diarrhéique apparaissant une douzaine d'heures après ingestion, dont les symptômes peuvent être confondus avec ceux provoqués par C. perfringens, et le céréulide, une toxine de type émétique, qui provoque des symptômes d'apparition beaucoup plus rapide ( 30 min à 6 h), comme ceux provoqués par les entérotoxines de $S$. aureus. Plusieurs décès ont été rapportés sur des personnes sensibles.

\section{Prévention}

Les aliments non consommés immédiatement après préparation, dans lesquels $B$. cereus peut être présent et se développer, doivent être maintenus au-dessus de $63^{\circ} \mathrm{C}$ ou surgelés, pour inhiber sa croissance, ou réfrigérés, pour la ralentir.

\section{Témoignage}

En 2018, la cuisine centrale d'une importante entreprise de restauration collective implantée en Nouvelle-Calédonie, semblait être à l'origine d'une série de 13 TIAC consécutives, apparues sur une période de 7 mois. Les investigations et les démarches analytiques ont révélé la présence fréquente et ubiquitaire de B. cereus, au sein de l'établissement. Ce pathogène a également pu être isolé d'aliments prélevés à différents stades de la préparation des repas, associé à d'autres catégories microbiennes: flores d'altération et parfois staphylocoques. La responsabilité de l'entreprise a été confirmée.

\section{Listeria}

(https://www.anses.fr/fr/content/fiche-de-description-de-da nger-biologique-transmissible-par-les-aliments-listeria-0)

\section{Caractéristiques bactériennes}

L. monocytogenes est un petit bacille Gram +, non sporulé, anaérobie facultative et microaérophile, qui peut croître aux températures comprises entre $-2^{\circ} \mathrm{C}$ et $45^{\circ} \mathrm{C}$, avec un optimum entre 30 et $37^{\circ} \mathrm{C}$. C'est une bactérie psychrotrophe capable de se développer aux températures de réfrigération. Elle possède la capacité de persister sur les surfaces des équipements agroalimentaires. On la retrouve donc dans des aliments à longue durée de vie, conservés sous régime du froid positif et dans les produits issus de l'industrie laitière.

\section{Sources}

L. monocytogenes est une bactérie ubiquitaire, tellurique, très largement répandue dans l'environnement. Les ensilages mal conduits peuvent être à l'origine de la contamination des ruminants. L'alimentation sous forme de soupe favorise la contamination des porcs. Elle occasionne souvent des problèmes en industrie laitière (surtout celles qui utilisent du lait cru).

\section{Manifestations cliniques}

L. monocytogenes est responsable d'une maladie grave (listériose) touchant l'Homme et les animaux. Le genre Listeria comporte à ce jour 21 espèces. Seules 2 espèces sont réputées pathogènes pour l'Homme et les animaux : L. monocytogenes, pathogène pour l'Homme et les animaux et $L$. ivanovii, pathogène pour les animaux et rarement pour l'Homme. Les femmes enceintes, les nouveau-nés ou les personnes immunodéprimées constituent des groupes à risque. Elle ne provoque pas de TIAC. C'est une zoonose, la contamination de l'Homme est d'origine alimentaire ou par contact avec des animaux malades. 
Prévention

Hygiène générale.

\section{Illustration}

Une épidémie de listériose qui a affecté 53 personnes et causé 10 décès entre 2015 et 2018 est survenue dans cinq États membres de l'UE (Autriche, Danemark, Finlande, Suède et Royaume-Uni) suite à la consommation de légumes congelés, maïs notamment, en provenance d'une usine hongroise (Source EFSA. Listeria dans les légumes surgelés : comment réduire les risques. 20.04.2020. Non publié).

\section{Autres bactéries}

\section{Clostridium botulinum}

(https://www.anses.fr/fr/content/fiche-de-description-de-da nger-biologique-transmissible-par-les-aliments-clostridium-2)

\section{Caractéristiques bactériennes}

Clostridium botulinum est un bacille Gram +, anaérobie strict, sporulé. Sa spore est particulièrement thermorésistante. C. botulinum sécrète une toxine thermosensible, qui inhibe la transmission de l'influx neuromusculaire. Cette toxine botulique est à ce jour considérée comme le poison le plus puissant au monde.

\section{Sources}

Les principales sources de contaminations sont d'origine telluriques (légumes, épices), ou animales lorsque les règles d'abattage ou de préparation des carcasses ne sont pas respectées (risque accentué pour les grosses pièces de viandes dont les parties profondes sont placées en zone anaérobie).

Les conserves familiales insuffisamment stérilisées, le jambon artisanal, sont souvent incriminés, et parfois le miel, chez les très jeunes enfants.

\section{Manifestions cliniques}

Les C. botulinum sont responsables de graves intoxications alimentaires chez l'Homme et les animaux (botulisme) par ingestion de toxine préformée dans un aliment (intoxination), ou par colonisation intestinale et production de toxine (toxi-infection).

On recense 5 à 15 foyers chaque année, avec 3 décès entre 2007 et 2017.

L'incubation dure 2 à 8 jours. La maladie se caractérise par des paralysies descendantes atteignant progressivement les muscles de l'accommodation et de la face, avec des difficultés de déglutition, sécheresse de la bouche, puis paralysie flasque des muscles respiratoires pouvant induire le décès par insuffisance respiratoire.

\section{Prévention}

Elle repose principalement sur le strict respect des règles de l'abattage, et notamment rapidité, réduction du stress ante mortem, respect de la diète avant abattage, saignée complète, refroidissement rapide, maintien en réfrigération, une stérilisation suffisante pour les produits appertisés.

\section{Escherichia coli entérohémorragiques (EHEC) \\ (https://www.anses.fr/fr/content/fiche-de-description-de-da nger-microbiologique-transmissible-par-les-aliments-escherichia)}

\section{Caractéristiques bactériennes}

C'est un bacille Gram -, oxydase négative, mesurant de 2 à $4 \mu \mathrm{m}$ de long et d'un diamètre d'environ 0,6 $\mu \mathrm{m}$. Certaines souches d'E. coli seulement sont pathogènes, car elles ont acquis des facteurs de virulence. Les souches les plus fréquemment impliquées dans les épidémies appartiennent aux sérotypes O26:H11, O103:H2, O111:H8, O145:H28 et O157:H7 ou encore O104:H4. Les EHEC libèrent des toxines (shigatoxines ou Stx, parfois appelées vérotoxines), induisant des lésions principalement intestinales, rénales et cérébrales.

Sources

Escherichia coli (E. coli) est normalement présent parmi le microbiote intestinal de l'Homme et des animaux à sang chaud. Sa présence dans les aliments témoigne d'une contamination fécale.

\section{Manifestions cliniques}

Les EHEC sont responsables de troubles variés allant d'une diarrhée aqueuse bénigne à une colite hémorragique pouvant évoluer vers des formes graves : syndrome hémolytique et urémique (SHU), principalement chez le jeune enfant, ou micro-angiopathie thrombotique (MAT) chez l'adulte.

\section{Illustration}

En Allemagne, en 2011, dans un communiqué commun, l'Institut fédéral d'évaluation des risques (BfR), l'Office fédéral de protection du consommateur et de sécurité alimentaire (BVL) et l'Institut Robert Koch ont tous les trois confirmé, vendredi 10 juin, que des graines germées (fenugrec notamment) étaient à l'origine de l'épidémie d'E. coli O104:H4.

\section{Yersinia enterocolitica}

(https://www.anses.fr/fr/content/fiche-de-description-de-da nger-biologique-transmissible-par-les-aliments-yersinia-0)

\section{Caractéristiques bactériennes}

C’est une entérobactérie Gram -, aéroanaérobie, mésophile.

Source

Les principales sources sont représentées par les amygdales (porcs \& sangliers), le tube digestif, les matières fécales, les mamelles et le sol. Les sérotypes 03 \& 09 sont les plus souvent incriminés. Les sérotypes les plus fréquemment rencontrés dans l'environnement ne sont pas pathogènes.

Manifestions cliniques

Chez l'enfant, l'incubation dure de 7 à 14 jours. La maladie se caractérise par une diarrhée aqueuse et des vomissements, parfois accompagnée d'une adénite mésentérique très douloureuse, simulant une crise d'appendicite, durant 1 à 2 semaines. Chez l'adulte, il s'agit généralement de diarrhées et d'arthrites. 
Prévention

Elle repose sur une éviscération rapide et soigneuse des animaux après abattage, le contrôle des pharynx, la cuisson de la viande de porc, le traitement thermique du lait, la bonne gestion du froid, la réduction des DLC.

\section{Brucella spp.}

(https://www.anses.fr/fr/content/fiche-de-description-de-danger-biologique-transmissible-par-les-aliments-brucella-spp)

\section{Caractéristiques bactériennes}

Brucella est un coccobacille à Gram -, intracellulaire facultatif.

\section{Sources}

La brucellose est une zoonose. La contamination de l'Homme peut se produire par consommation d'aliments contaminés, essentiellement lait et produits laitiers crus, mais aussi par contact de la peau ou des muqueuses avec des animaux infectés ou leurs produits. Les principaux réservoirs animaux des Brucella sont les bovins (B. abortus), les ovins et caprins (B. melitensis) et les porcins domestiques (B. suis).

\section{Manifestions cliniques}

Fièvre ondulante, sueurs abondantes, arthralgies/myalgies, fatigue, sensation de malaise, céphalées, syndrome pseudo-grippal. L'évolution sous forme chronique est fréquente.

\section{Prévention}

En l'absence d'information sur la situation sanitaire du pays, ne pas consommer les produits laitiers non pasteurisés ou non stérilisés.

\section{Cronobacter (ex Enterobacter) sakazakii et autres espèces} (https://www.anses.fr/fr/system/files/BIORISK2016SA008 2Fi.pdf)

\section{Caractéristiques bactériennes}

C'est un opportuniste responsable d'infections graves, surtout chez le nouveau-né prématuré.

\section{Sources}

Elles sont représentées par les préparations en poudre pour nourrissons et aliments diététiques en poudre destinées à des fins médicales pour nourrissons de moins de 6 mois.

\section{Manifestions cliniques}

Environ six nouveaux cas d'infections à Cronobacter sont rapportés chaque année à travers le monde. L'incidence est rare, probablement sous-estimée, mais présente une létalité élevée, caractérisée par des entérocolites nécrosantes, des septicémies ou des méningites.

\section{Vibrio parahaemolyticus}

(https://www.anses.fr/fr/system/files/BIORISK2016SA027 2Fi.pdf)

\section{Caractéristiques bactériennes}

C'est un bâtonnet Gram -, en virgule, halophile (0,5 à $10 \%$ de $\mathrm{NaCl}$ ), aéro-anaérobie facultatif.
Sources

Elles sont représentées par les sédiments, le plancton, les crustacés, les mollusques et les poissons des milieux estuariens et marins surtout tropicaux. C'est la première cause de toxi-infections au Japon.

\section{Manifestions cliniques}

L'incubation dure 15 à $24 \mathrm{~h}$. La maladie est due à une toxine hémolysante qui provoque : douleurs abdominales, crampes, diarrhées aqueuses, parfois nausées, vomissements et fièvre.

\section{Prévention}

Elle repose sur la prohibition de certaines zones de pêche, la réfrigération, la cuisson, le respect de l'hygiène, les alertes à l'import, etc.

\section{Vibrio cholerae}

(https://www.anses.fr/fr/system/files/BIORISK2016SA027 2Fi.pdf)

Le choléra est une maladie exclusivement humaine avec pour seul réservoir l'être humain. Il concerne surtout les zones surpeuplées et défavorisées (malnutrition et absence d'hygiène hydrique).

\section{Campylobacter}

(https://www.anses.fr/fr/content/fiche-de-description-de-da nger-biologique-transmissible-par-les-aliments-campylobacter-0)

\section{Caractéristiques bactériennes}

Les Campylobacter sont des bacilles mésophiles Gram -, de forme spiralée ou incurvée, pouvant évoluer vers une forme coccoïde, Le genre Campylobacter comporte une trentaine d'espèces ou sous-espèces se développant toutes à $37^{\circ} \mathrm{C}$, et certains Campylobacter thermo-tolérants de manière optimale à $41,5^{\circ} \mathrm{C}$. Leur croissance est favorisée dans une atmosphère appauvrie en oxygène, enrichie en $\mathrm{CO}_{2}$. Ces bactéries ne se multiplient pas dans les aliments et ne forment pas de spores, Campylobacter jejuni et, dans une moindre mesure, C. coli sont à l'origine de la très grande majorité des cas de campylobactérioses humaines d'origine alimentaire, qui se présentent habituellement sous forme de cas sporadiques.

\section{Sources}

Les oiseaux, sauvages et domestiques, sont considérés comme les principaux réservoirs de Campylobacter jejuni et dans une moindre mesure, de C. coli. D'autres réservoirs ont été décrits : les bovins, les porcins, les petits ruminants, et en particulier les chiots et les chatons diarrhéiques.

La principale voie de transmission de Campylobacter à l'Homme est indirecte par l'ingestion d'aliments contaminés, y compris les eaux de boisson.

\section{Manifestions cliniques}

Chez l'Homme, après une durée d'incubation de 1 à 8 jours, apparaissent les manifestations de l'infection à dominante abdominale : diarrhées, douleurs abdominales, selles sanglantes, fièvre, céphalées, vomissements plus rares. 


\section{ANALYSES MICROBIOLOGIQUES DE ROUTINE : INTÉRÊT ET SIGNIFICATION}

(Sutra et al.1998)

(Règlement (CE) n 2073/2005 de la commission du 15 novembre 2005 concernant les critères microbiologiques applicables aux denrées alimentaires)

\section{Flore mésophile}

La flore aérobie mésophile (FAM, nommée aussi flore totale) est constituée d'un ensemble de microorganismes mésophiles et aérophiles, bactéries spécifiques ou non, sans que l'on cherche à distinguer les espèces auxquelles elles appartiennent. Elle englobe les Pseudomonas, la flore lactique, levures, moisissures, entérobactéries, coliformes fécaux ou non, E. Coli, etc. dans des proportions variables selon les produits et les conditions. Des analyses plus fines sont nécessaires pour connaître et quantifier différentes populations microbiennes présentes. La flore aérobie mésophile permet d'évaluer la contamination globale d'un produit, son aptitude à la conservation, de suspecter une éventuelle rupture de la chaîne du froid (conjectures sur l'histoire du produit). Elle permet aussi d'évaluer la qualité d'une opération de nettoyage-désinfection de surface. Si cette opération a été efficace, la surface traitée devrait être stérile. Les différents composants de cette flore peuvent aboutir à des dégradations de la qualité des aliments. En quantité trop importante, ils sont susceptibles d'engendrer des manifestions cliniques à prédominance digestive.

\section{Entérobactéries}

Les entérobactéries peuvent être de bons indicateurs de l'hygiène générale de l'entreprise et des processus de fabrication, mais elles ne constituent pas pour autant un indicateur de la présence ou de l'absence de microorganismes pathogènes. Elles sont elles-mêmes constituées de plusieurs groupes bactériens : coliformes totaux, coliformes fécaux, E. coli, Salmonella, notamment. Leur valeur en qualité de témoin de contamination fécale varie. Les entérobactéries présentent la valeur la plus faible, ensuite viennent les coliformes totaux, puis les coliformes fécaux. La présence d'E. coli témoigne de la plus forte spécificité d'une contamination fécale, révélatrice d'un défaut d'hygiène majeur.

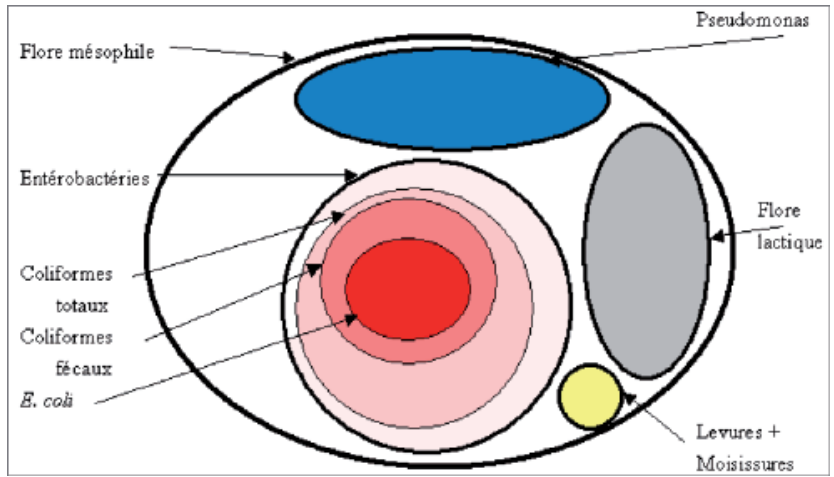

Figure 1 : Représentation schématique des composants de la flore mésophile

\section{Pseudomonas}

Les Pseudomonas sont des bactéries aérobies strictes, psychrotrophes qui se multiplient très bien dans les produits alimentaires d'origine animale ou végétale, à partir de $+4^{\circ} \mathrm{C}$.

Les Pseudomonas sont présents dans les produits carnés, laitiers et végétaux, le sol et les eaux.

Ils sont dotés d'un important équipement enzymatique constitué de protéases et de lipases, responsables de l'altération des substrats, engendrant la formation de nombreux produits de dégradation.

Ils présentent un intérêt technologique, car ils constituent un facteur limitant pour la conservation des produits alimentaires. Leur présence se traduit par l'apparition d'un enduit visqueux microbien en surface, modifiant aspect, odeur et goût. Lorsqu'ils sont présents sur les produits sous vide, ils témoignent d'une mauvaise qualité (ou rupture) du sous vide.

\section{Flore lactique}

Elle est essentiellement constituée de Streptococcus et Lactobacillus, généralement non sporulés, anaérobies ou micro-aérophiles. Sa présence aboutit à la fermentation des sucres en acide lactique ou en mélange acide lactique, $\mathrm{CO}_{2}$, éthanol ou acide acétique (bactéries acidifiantes). Elle trouve sa source dans le sol, les plantes en décomposition, les animaux (tractus gastro-intestinal, fèces et lait).

Bien maitrisée, elle présente un grand intérêt technologique : fabrication de légumes fermentés (choucroute), produits laitiers (yaourts, fromages), charcuterie (jambons, saucissons), etc. Dans les viandes sous vide, elle peut servir d'auxiliaire technologique en luttant contre l'envahissement par les bactéries putréfiantes telle que les Pseudomonas. Elle peut constituer un indice d'altération des denrées sous vide : exsudat et enduit bactérien, acidification et parfois gonflement. Son dénombrement est utile pour apprécier la « fraîcheur » d'un produit.

\section{Levures et moisissures}

Elles appartiennent à un groupe microbien très ubiquitaire, aérobies ou non. Elles sont capables d'altération de tous les produits alimentaires, ou bien de participer à des processus technologiques bien connus tels que la vinification ou la fabrication de fromages.

\section{Interprétation des résultats d'analyse}

Le tableau 1 (en fin d'article) est un guide d'interprétation des résultats d'analyse. Il synthétise l'ensemble des données présentées plus haut. Il constitue une aide à l'interprétation des résultats d'analyses microbiologiques : paramètres, signification, origine, et conduite à tenir (source A. Guignard, 2021). 


\section{PRODUIT DU MÉTABOLISME BACTÉRIEN : HISTAMINE}

(https://www.anses.fr/fr/content/fiche-de-description-de-danger-biologique-transmissible-par-les-aliments-histamine)

Sources et origine

Les poissons dont la chair est riche en histidine (principales familles concernées : Scombridae Clupeidae, Engraulidae, Coryphaenidae, Pomatomidae, Scomberesocidae), constituent les denrées le plus souvent mises en cause. Sous l'action des enzymes des bactériennes (entérobactéries mésophiles, bactéries psychrotrophes, notamment) l'histidine est transformée en histamine, par décarboxylation. Un tel mécanisme peut survenir au sein d'autres matrices (fromages, boissons alcoolisées, charcuteries, légumes, etc.) et aboutir à la synthèse d'autres amines biogènes (tyramine, cadavérine, etc.). L'histamine est une molécule thermostable qui résiste à l'appertisation.

\section{Manifestations cliniques}

Les principaux symptômes de l'intoxication histaminique (ou syndrome de pseudo-allergie alimentaire) sont liés à l'effet vasodilatateur de l'histamine. L'incubation est très courte, de quelques minutes à quelques heures après la consommation, dose dépendante, avec des variations selon les sensibilités individuelles. Les symptômes se caractérisent par : rougeur facio-cervicale, éruption cutanée, œè̀me du visage, bouffées de chaleur, sensation de brûlure dans la gorge, goût de poivre dans la bouche, démangeaisons, picotements de la peau, céphalées, palpitations cardiaques, étourdissements. L'évolution est habituellement favorable en quelques heures.

\section{Témoignage}

Au cours d'une période de 16 ans (période de 1987 à 2003 inclus), le laboratoire national vétérinaire de Rungis a été sollicité pour analyser des produits concernant 126 foyers de suspicions de TIAC à histamine (presque 8 par an), pour les 8 départements d'Île-de-France. 66 foyers ont été confirmés (52\%). (Non publié). Les teneurs en histamine variaient depuis des "traces" ou présence $<100 \mathrm{mg} / \mathrm{kg}$ : 7 (dont 1 sauce nem), 100 $\mathrm{mg} / \mathrm{kg}$ : 4 (dont 1 fromage), $200 \mathrm{mg} / \mathrm{kg}: 7$ (dont 1 fromage), jusqu'à $4000 \mathrm{mg} / \mathrm{kg}$. La répartition des 66 produits incriminés étaient conformes aux données de la littérature : thon : 54 $(82 \%)$, raie : $2(3 \%)$, espadon : $2(3 \%)$, saumon : $1(1,5 \%)$, sardine : $1(1,5 \%)$, maquereau : $1(1,5 \%)$, sauce nem : $1(1,5 \%)$, fromage : 2 (3\%), inconnu : $2(3 \%)$.

\section{Prévention}

Elle repose sur l'hygiène des opérations, saignée rapide, refroidissement rapide à cœur, respect de la chaîne du froid.

\section{VIRUS}

\section{Norovirus}

(https://www.anses.fr/fr/content/fiche-de-description-de-da nger-biologique-transmissible-par-les-aliments-nor ovirus-mai-2011)
Caractéristiques virales

Ce sont de petits virus non enveloppés, possédant une capside à symétrie icosaédrique, d'environ $27 \mathrm{~nm}$ de diamètre. Leur génome est constitué d'un ARN monocaténaire. Ils peuvent résister aux traitements d'épuration.

\section{Sources}

L'Homme infecté constitue le seul réservoir des norovirus humains. Manifestions cliniques

Les norovirus (NoV) constituent la principale cause de gastroentérites aiguës (GEA) chez l'Homme toutes classes d'âge confondues. La durée moyenne d'incubation est de 10 à 50 heures. Les principaux symptômes sont : gastro-entérite aiguë avec apparition brutale de vomissements, nausées et/ou de diarrhée parfois associés à des crampes abdominales, malaise, anorexie, fièvre (peu élevée, rapportée dans moins de $50 \%$ cas), frissons, courbatures et maux de tête. La durée des symptômes atteint : 2 à 3 jours, parfois plus, jusqu'à 6 jours. Le décès peut survenir.

\section{Rotavirus}

(https://www.anses.fr/fr/content/fiche-de-description-de-da nger-biologique-transmissible-par-les-aliments-rotavirus-juillet-0)

Caractéristiques virales

Ce sont des virus à ARN bicaténaire non enveloppés, en forme de roue, de $100 \mathrm{~nm}$ de diamètre.

Grâce à leur triple couche protéique protectrice, les rotavirus persistent plusieurs semaines dans le milieu extérieur.

Sources

L’Homme est le principal réservoir des rotavirus humains.

Manifestions cliniques

La durée moyenne d'incubation est de 3 jours. La population la plus à risque est représentée par les enfants de moins de 5 ans. Les principaux symptômes se caractérisent par : gastroentérite aigüe, apparition rapide de vomissements et de diarrhées, déshydratation rapide, fièvre modérée. Complications : méningites, encéphalites dans de très rares cas. Ils durent de 3 à 7 jours.

\section{Virus de I'hépatite A}

(https://www.anses.fr/fr/content/fiche-de-description-de-da nger-biologique-transmissible-par-les-aliments-virus-de-lhep $\underline{\text { atit-0) }}$

\section{Caractéristiques virales}

C'est un virus non enveloppé de 28 à $30 \mathrm{~nm}$ de diamètre, dont le génome est constitué d'un ARN monocaténaire.

\section{Sources}

L'Homme infecté est considéré comme le seul réservoir de virus (excrétion dans les selles). Le VHA étant très résistant aux conditions environnementales, il peut persister dans le milieu extérieur et rester infectieux plusieurs semaines notamment dans les eaux usées contaminées et sur les produits irrigués. 
Manifestions cliniques

La durée moyenne de l'incubation est de 30 jours (15-50 jours). Les principaux symptômes sont : syndrome pseudo-grippal, troubles digestifs (nausées, douleurs abdominales), ictère. La surveillance de l'hépatite A en France est basée sur la déclaration obligatoire mise en place depuis 2006.

\section{Virus de l'hépatite $\mathrm{E}$}

(https://www.anses.fr/fr/content/fiche-de-description-de-da nger-biologique-transmissible-par-les-aliments-virusde-1\%E2\%80\%99h\%C3\%A9pati-0)

\section{Caractéristiques virales}

Le virus de l'hépatite $\mathrm{E}$ (VHE) est un virus ARN monocaténaire, non enveloppé de 30 à $34 \mathrm{~nm}$ de diamètre qui possède une capside de symétrie icosaédrique.

\section{Sources}

Dans les pays industrialisés, plusieurs espèces animales sont susceptibles d'héberger le virus, mais le principal réservoir animal du VHE est le porc et plus généralement les suidés. Dans les pays industrialisés, le VHE n'est pas transmis sous forme épidémique interhumaine et la plupart des cas sont d'origine inconnue. Néanmoins, le VHE peut être à l'origine de cas de transmissions zoonotiques par la voie alimentaire.

\section{Manifestions cliniques}

Le virus de l'hépatite $\mathrm{E}$ (VHE) reste la principale cause d'hépatites aiguës évoluant sur un mode endémo-épidémique dans les régions tropicales et subtropicales où l'hygiène la plus élémentaire, c'est-à-dire l'accès à l'eau potable fait défaut. La durée moyenne d'incubation est 40 jours (15-60 jours). Les principaux symptômes sont : ictère (75\%), anorexie (45\%), syndrome pseudo-grippal (40\%).

\section{CHAMPIGNONS ET LEURS TOXINES}

\section{Aflatoxines et Aspergillus flavus}

(https://www.anses.fr/fr/content/fiche-de-description-de-da nger-biologique-transmissible-par-les-aliments-aspergillus-flavu-0) (Bauduret \& Guignard, 1988)

\section{Caractéristiques}

L'aflatoxine B1 (AFB1), est considérée comme l'un des plus puissants cancérogènes génotoxiques naturels. Son organe cible est le foie. Aspergillus flavus est la principale espèce productrice d'aflatoxines (uniquement du groupe B). D'autres Aspergillus produisent en plus des aflatoxines du groupe $G$, mais ces autres champignons microscopiques (moisissures) ne sont rencontrés que très rarement dans les aliments.

\section{Sources}

Les aflatoxines sont produites au champ ou lors du stockage, principalement en zones de climat subtropical ou méditerranéen, mais également dans les zones tempérées en cas de saisons particulièrement chaudes et sèches. A. flavus est responsable de la contamination des céréales (principalement le maïs et les produits à base de maïs), des graines oléagineuses et des tourteaux destinés à l'alimentation animale, des fruits à coques (comme les arachides et les pistaches), des épices de toutes sortes, des fruits secs (comme les figues), du café, des fèves de cacao. On peut aussi retrouver des aflatoxines AFM1 dans le lait produit par des vaches laitières ayant consommé des aliments contaminés par des AFB1.

\section{Manifestions cliniques}

Lors d'une intoxication aiguë, les symptômes cliniques typiques, mais non spécifiques incluent ictère, dépression, anorexie et diarrhées. Les intoxications chroniques peuvent induire des cancers du foie. Plusieurs cas d'aflatoxicose aiguë survenus en élevage, notamment chez les porcins, ont été décrits. La mort des animaux est le plus souvent survenue en quelques heures après un épisode hémorragique sévère. Chez les volailles la forme chronique de l'intoxication est la plus fréquente. Elle se manifeste par une diminution des performances associée à des hémorragies et des défauts de pigmentation des carcasses.

\section{Ochratoxine A (OTA)}

(https://www.anses.fr/fr/content/fiche-de-description-de-da nger-biologique-transmissible-par-les-aliments-aspergilli-et)

\section{Caractéristiques}

Les espèces principales qui produisent de l'OTA, mycotoxine à effet néphrotoxique, sont : Aspergillus carbonarius et des espèces proches, A. ochraceus, Penicillium verrucosum, etc.

\section{Sources}

L'OTA est considérée comme une " mycotoxine de stockage " pour les céréales et une "mycotoxine des champs " pour la vigne. Elle est produite sous les climats froids et tempérés par $P$. verrucosum (céréales) et $A$. carbonarius (vigne) et, en régions tropicales et chaudes par A. ochraceus (café vert, cacao, oléo-protéagineux). L'OTA est susceptible de s'accumuler dans la chair des animaux ayant consommé des aliments contaminés. L'Homme s'expose par la consommation d'aliments contaminés par l'OTA.

\section{Manifestions cliniques}

L'OTA a principalement des effets néphrotoxiques. L'OTA est classée dans la catégorie des agents peut-être cancérogènes pour l'Homme.

\section{Patuline}

(https://www.anses.fr/fr/content/fiche-de-description-de-da nger-biologique-transmissible-par-les-aliments-penicillium-0)

\section{Caractéristiques}

Les espèces principales qui produisent de la patuline sont : Penicillium expansum (le plus important du point de vue sanitaire et économique) et d'autres champignons microscopiques (moisissures) comme Penicillium, Aspergillus, Byssochlamys, etc. 
Sources

P. expansum est saprophyte de la pomme, où il peut se développer sous forme de nécrose en disque. Il est le responsable majeur de la contamination par la patuline des jus de fruits, compotes et autres produits de la transformation des pommes.

\section{Manifestions cliniques}

La patuline est reconnue pour provoquer des désordres gastro-intestinaux avec ulcérations, distensions et hémorragies, voire des perturbations de la fonction rénale, à plus forte dose.

\section{Amanite phalloïde et autres champignons responsables du syndrome phalloïdien}

\section{(https://www.anses.fr/fr/content/fiche-de-description-de-da nger-biologique-transmissible-par-les-aliments-lamanite-pha lloide)}

\section{Caractéristiques}

L'amanite phalloïde est responsable d'une grande majorité des intoxications mortelles par ingestion de champignons et de 90\% des cas de syndrome phalloïdien.

\section{Sources}

Le syndrome phalloïdien est un syndrome mycotoxique tardif (latence supérieure à six heures après l'ingestion des champignons). Les neuf toxines incriminées sont stables à la cuisson, la stérilisation et la congélation.

\section{Manifestions cliniques}

De 10 à $12 \mathrm{~h}$ après l'ingestion, des troubles gastro-intestinaux sévères, suivis, entre 36 et 48 h après l'ingestion, d'une cytolyse hépatique grave aboutissant à une insuffisance hépatocellulaire, encéphalopathie hépatique, coma, et éventuellement décès.

\section{PARASITES}

\section{Trichines}

(https://www.anses.fr/fr/content/fiche-de-description-de-da nger-biologique-transmissible-par-les-aliments-trichine lla-spp-mai)

\section{Principales caractéristiques biologiques}

Trichinella est un ver rond parasite appartenant à la classe des Nématodes. Le ver se trouve sous sa forme larvaire infectante dans les fibres musculaires striées des mammifères essentiellement (surtout omnivores et carnivores, parfois chevaux). Ils se contaminent en ingérant des muscles parasités (accidentellement pour les herbivores).

\section{Sources}

La principale source est représentée par la viande crue ou peu cuite de sanglier, de porc, ou de cheval. Les cas importés sont principalement liés à la consommation de viandes de gibiers : ours, phacochère, etc.
Manifestions cliniques

Chez l'Homme, après une durée d'incubation de 5 à 21 jours, le développement des formes adultes dans l'intestin provoque des douleurs abdominales et éventuellement une diarrhée non sanglante. La migration des larves nouveau-nées dans la circulation se traduit par une fièvre élevée et des manifestations allergiques (œè̀me de la face, éruption cutanée, etc.). La pénétration des larves dans les cellules musculaires se traduit par des myalgies intenses. Cette phase fébrile dure une dizaine de jours, disparaît spontanément, laissant place à une longue asthénie et souvent à des myalgies chroniques.

\section{Anisakis}

(https://www.anses.fr/fr/content/fiche-de-description-de-da nger-biologique-transmissible-par-les-aliments-anisakis-spp-0)

Principales caractéristiques biologiques

La famille des Anisakidae comprend plusieurs genres parmi lesquels Anisakis (dont l'espèce A. simplex) et Pseudoterranova. Ils provoquant la même maladie (anisakidose). Les larves mesurent environ deux centimètres et sont présentes dans la cavité abdominale des poissons, ou plus souvent plaquées à la surface du mésentère et des organes, plus rarement présentes dans le tissu musculaire, enroulées en spirale ou libres. L'anisakidose est une zoonose cosmopolite, les Anisakidae étant présents dans toutes les mers et océans. Tous les vertébrés homéothermes piscivores peuvent être l'objet d'un parasitisme par les larves d'Anisakidae. Selon les zones, jusqu'à $100 \%$ des poissons de mer et 20 à $35 \%$ des céphalopodes sont parasités.

\section{Sources}

La transmission à l'Homme est quasi-exclusivement alimentaire, par consommation de poisson cru ou peu cuit.

Manifestions cliniques

Chez l'Homme, après une durée d'incubation d'une heure à plus de cinq jours, apparaissent, soit des troubles gastro-intestinaux : douleurs abdominales, nausées, vomissements, diarrhées, ou manifestations pseudo-ulcéreuses, syndromes appendiculaires, péritonéaux, rares formes coliques ou iléales basses, soit des manifestations de type allergique, de quelques heures à 24 heures : allergies digestives, urticaire, provoqués par des larves vivantes, allergies cutanées et/ou respiratoires, angiœedème, provoquées par des larves vivantes ou mortes.

\section{Autres parasites}

De nombreux autres parasites peuvent provoquer des troubles. Bien que moins fréquemment rencontrés, ils sont susceptibles de créer des problèmes de santé publique. On peut citer de façon non exhaustive :

Cryptosporidium spp. (parasite unicellulaire), agent de la cryptosporidiose, à l'origine de troubles gastro-intestinaux dominés par une diarrhée.

(https://www.anses.fr/fr/content/fiche-de-description-de-da nger-biologique-transmissible-par-les-aliments-cryptospor idium-s-0) 
Diphyllobothriocephalus (ver plat rubané) agent de la diphyllobothriose, à l'origine de troubles digestifs et généraux persistants.

(https://www.anses.fr/fr/content/fiche-de-description-de-da nger-biologique-transmissible-par-les-aliments-diphyllob othrium-0)

Fasciola hepatica, (ver plat non segmenté) ou grande douve du foie, agent de la fasciolose, à l'origine de graves troubles hépatiques et généraux.

(https://www.anses.fr/fr/content/fiche-de-description-de-da nger-biologique-transmissible-par-les-aliments-fasciola-hep atica-0)

Taenia saginata (ver plat), un des deux agents responsables du téniasis humain, à l'origine de prurit anal, avec douleurs abdominales, nausées, amaigrissement.

(https://www.anses.fr/fr/content/fiche-de-description-de-da nger-biologique-transmissible-par-les-aliments-t\%C3\%A6niasaginata-0)

Taenia solium (ver plat), un des deux agents responsables du téniasis humain, responsable en outre de la cysticercose, infection de l'Homme par le stade larvaire de T. solium (Cysticercus cellulosae). La gravité dépend de la nature des organes atteints par les larves. Cette parasitose est rarissime en France métropolitaine.

(https://www.anses.fr/fr/content/fiche-de-description-de-da nger-biologique-transmissible-par-les-aliments-t $\%$ C3\%A6nia$\underline{\text { solium-0) }}$

Toxoplasma (parasite intracellulaire), agent de la toxoplasmose, à l'origine de manifestations généralement asymptomatiques ou bénignes mais graves en cas d'atteintes pulmonaires, neurologiques, oculaires, ou materno-foetales.

(https://www.anses.fr/fr/content/fiche-de-description-de-da nger-biologique-transmissible-par-les-aliments-toxoplasma-go $\underline{\text { ndii-0) }}$

Echinococcus multilocularis un (petit) tænia agent d'une zoonose parasitaire provoquant une maladie hépatique potentiellement grave, l'échinococcose alvéolaire.

(https://www.anses.fr/fr/content/fiche-de-description-de-da nger-biologique-transmissible-par-les-aliments-echinococcus-0)

Giardia (protozoaire), agent de la giardiose, à l'origine de troubles digestifs, et de retard de croissance en cas d'infection chronique chez l'enfant.

(https://www.anses.fr/fr/content/fiche-de-description-de-da nger-biologique-transmissible-par-les-aliments-giardia-duod enali-0)

Entamoeba histolytica : E. histolytica / E. dispar, (pathogène eucaryote unicellulaire), à l'origine de troubles digestifs généralement peu symptomatiques mais pouvant être très graves.

(https://www.anses.fr/fr/content/fiche-de-description-de-da nger-biologique-transmissible-par-les-aliments-entamoeba-0)

Ascaris suum (nématode), à l'origine d'un syndrome abdominal essentiellement chez l'enfant associant collique, diarrhée, vomissements et des symptômes associés hépatiques ou pulmonaires liés aux larva migrans (Charpenay, 2012).
Echinococcus granulosus (cestode), à l'origine d'une symptomatologie qui dépend de la localisation des kystes larvaires (hydatides) (Charpenay, 2012).

Sarcocystis spp. (pathogène eucaryote unicellulaire), affection généralement asymptomatique chez l'individu immunocompétent (Charpenay, 2012).

Cyclospora cayetanensis (parasite unicellulaire), à l'origine d'un syndrome abdominal pouvant être grave surtout chez l'individu immunodéprimé, aire d'extension géographique essentiellement intertropicale.

(https://www.anses.fr/fr/content/fiche-de-description-de-da nger-biologique-transmissible-par-les-aliments-cyclospora-1)

\section{PHYCOTOXINES ET TOXINES MARINES}

(La Vieille et al. 2004)

DSP, PSP, ASP

La multiplication des efflorescences d'algues potentiellement toxiques est à l'origine de problèmes de sécurité sanitaire pour ce qui concerne les eaux de boisson et les produits de la pêche, les coquillages ou les poissons. À ce jour, on distingue :

- Les " toxines diarrhéiques (DSP) " comprenant plusieurs composés dont le plus connu est l'acide okadaïque. Les signes cliniques apparaissent en moyenne 4 heures après l'ingestion des coquillages contaminés : diarrhées, vomissements et douleurs abdominales. Ces symptômes disparaissent après 3 jours sans séquelles.

- Les " toxines paralysantes (PSP) " forment une famille de molécules dont la toxine de base est la saxitoxine. Les signes d'intoxication apparaissent très rapidement après l'ingestion et la gravité dépend de la dose ingérée ainsi que de la sensibilité individuelle. Le rétablissement est généralement total en quelques jours mais pour les cas les plus graves, les consommateurs peuvent mourir des suites d'une paralysie respiratoire. Les symptômes sont à dominance nerveuse de type paresthésies. Il n'existe pas d'antidote connu.

- Les « toxines amnésiantes (ASP) » : la phycotoxine identifiée est l'acide domoïque. Peu de temps après l'ingestion, les patients montrent des signes classiques d'intoxication alimentaire : vomissements, crampes abdominales, diarrhée, etc. environ 2 jours plus tard, des troubles neurologiques apparaissent : céphalées, troubles de la mémoire, confusion, coma... Habituellement, la récupération intervient dans un délai de 1 à 4 jours, mais on a déjà enregistré des morts parmi les malades atteints de convulsions graves.

\section{Le groupe ciguatoxines, phycotoxines et autres toxines non encore identifiées en France métro- politaine}

(Quod JP et al. 1994 ; Quod JP et al. 1990)

(https://www.anses.fr/fr/content/avis-et-rapport-de-lansesrelatifs-\% C3\% A $0-1 \%$ C $3 \%$ A 9 valuation-du-risqueli\%C3\%A9-\%C3\%A0-la-consommation-de-deux)

Les toxines ciguatériques, retrouvées chez certaines espèces de 
poissons, généralement gros carnivores tels que mérous, carangues, lutjanus, barracudas, en milieu tropical, des Caraïbes, de l'océan Indien et de l'océan Pacifique, provoquent la maladie appelée ciguatéra. Pathologie endémique dans les régions concernées où la population consomme beaucoup de poisson. Elle provoque des symptômes de type gastro-intestinal associés à des symptômes neurologiques notamment des paresthésies, l'inversion des sensations du chaud et du froid, et de fortes démangeaisons. Cette maladie est d'ailleurs communément surnommée, dans les zones d'endémies "maladie de la gratte". Des problèmes cardio-vasculaires peuvent aussi survenir : hypotension artérielle et troubles du rythme cardiaque. Les décès sont toutefois très rares. Les dinoflagellés producteurs de ciguatoxines, ainsi que les poissons vecteurs ont aussi été trouvés en Méditerranée et en Atlantique (Madère).

\section{Autres toxines}

A côté de ces groupes les mieux connus, il existe d'autres toxines telles que les brévétoxines, et plus récemment les azaspiracides. Les symptômes de toutes les intoxications sont à dominance digestive ou neurologique. La liste risque de continuer à s'allonger, car l'univers marin est loin d'avoir révélé tous ses secrets.

\section{AGENT TRANSMISSIBLE NON CONVENTION- NEL (ATNC) : ENCÉPHALOPATHIE SPONGIFORME BOVINE (ESB)}

(https://www.anses.fr/fr/system/files/BIORISK2016SA0153Ra.pdf)

Les encéphalopathies spongiformes transmissibles, ou maladies à prions sont des maladies humaines et animales affectant le système nerveux central. Certaines d'entre elles sont transmissibles par voie alimentaire, et plus spécialement à partir de certains tissus ou matériel à risque spécifié (MRS). Elles sont induites par des agents transmissibles non conventionnels (ATNC) également appelés prions particulièrement résistants aux processus d'inactivation. Chez l'Homme, on observe des troubles psychiatriques, ataxie cérébelleuse, évoluant lentement (plus d'un an) et irrémédiablement vers la mort.

\section{ALLERGIES ALIMENTAIRES D'ORIGINE ANIMALE - INTOLÉRANCE ALIMENTAIRES - FAUSSES ALLERGIES ALIMENTAIRES}

(Ancellin et al. 2002).

\section{L'allergie alimentaire « vraie »}

Par opposition aux fausses allergies alimentaires, elle correspond à des manifestations cliniques apparaissant après l'ingestion d'un allergène alimentaire (trophallargènes). Elleimpliquent un mécanisme immunologique à base $\operatorname{IgE}$ qui se manifeste lors d'un second contact après une phase initiale de sensibilisation. Les principaux allergènes alimentaires (des protéines de poids moléculaires moyens) d'origine animale se trouvent dans le lait de vache, les œufs, le poisson, les crustacés et rarement les mollusques et les viandes (de porc). Les signes cliniques associés à une allergie alimen- taire sont divers et non spécifiques, gastro-intestinaux, dermatites, asthme, œdème de Quincke, choc anaphylactique, etc.

\section{Les fausses allergies alimentaires}

Il ne s'agit pas d'un mécanisme immuno-allergique. Les manifestations sont consécutives à la consommation d'aliments riches en histamine préformée, d'autres amines comme la tyramine, ou des aliments contenant des substances histamino-libératrices (Voir plus haut, $\S$ histamine). Les principaux aliments riches en histamine préformée sont des produits fermentés tels que fromages, choucroute, vin, aliments fumés, poissons, crustacés ; les aliments riches en tyramine : certains fromages, chocolat, hareng saur ; ceux provoquant la libération d'histamine : fraises, tomates, blanc d'œuf, crustacés. L'ensemble des manifestations suite à la consommation de ces aliments sont sensiblement les mêmes que celles observées lors des allergies, mais par un mécanisme différent.

\section{Les intolérances alimentaires}

Ce sont des réactions qui ne font pas intervenir de mécanismes immuno-allergiques. L'exemple classique est l'intolérance au lactose par déficit enzymatique en lactase entrainant la disparition de la capacité à digérer le lactose, se traduisant par un syndrome abdominal.

\section{RISQUES CHIMIQUES}

(Bulletin épidémiologique Anses-DGAL, numéro spécial, 2017) (https://www.anses.fr/fr/system/files/BIORISK2016SA0153Ra.pdf)

Très nombreux, on peut citer : anabolisants, résidus de médicaments, pesticides, dioxines, mélamine, toutes substances interdites ou dangereuses, etc.

\section{SYNDROMES COLLECTIFS INEXPLIQUÉS - PHÉNOMĖNES PSYCHOGÈNES}

\section{(Kermarec et al. 2010 ; Watrin M. \& Erouart S. 2012)}

Des syndromes collectifs inexpliqués présentant une symptomatologie neurologique et/ou digestive non spécifique, notamment sur des groupes d'enfants, sans explication rationnelle objective, nommés phénomènes psychogènes, tant du point de vue environnemental qu'alimentaire se rencontrent parfois. Ce type d'évènements, qui dépassent le strict cadre de la sphère digestive, a fait l'objet d'un guide édité par l'INVS, pour le diagnostic et la prise en charge des syndromes collectifs inexpliqués.

\section{CONCLUSION}

Les dangers liés à la consommation alimentaire sont divers et variés. L'ensemble des éléments présentés concrétise, une fois de plus, la réalité du concept "One world-One health ». La mise en œuvre de bonnes pratiques d'hygiène, de la "fourche à la fourchette " permettent de se prémunir de ces dangers. Il convient également de rester vigilant devant les risques d'introduction dans l'alimentation, de produits indésirables, de corps étrangers, de façon fortuite, suite à des actes de malveillance, et plus grave encore, dans un contexte où le terrorisme alimentaire est toujours possible. 
Au cours de ma carrière, il m'est arrivé de recevoir des personnes de bonne foi, excessivement inquiètes, suspectant leurs proches de vouloir les empoisonner. Cela génère toujours un très fort sentiment de malaise, sans savoir si ces suspicions sont fondées ou non.
Les habitudes alimentaires évoluent, les échanges internationaux et la technologie nous proposent des produits nouveaux, qui ne sont pas familiers pour nos organismes. De nouveaux dangers sont donc susceptibles d'émerger. L'avenir nous réserve probablement encore de grandes surprises.

\section{REMERCIEMENTS}

À l'ensemble des agents du laboratoire vétérinaire départemental de la Réunion, des laboratoires de l'ANSES, au laboratoire national vétérinaire de Rungis et en particulier à mes prédécesseurs à ce poste (André Petit, Anne-Marie Vanelle), et mes anciens collègues (Sabine Herbin, Sophie Trotereau, Gaëlle Lattard, Anne-Laure Flavigny), Alain Bonneau de la DRIAAF Île-de-France, Renaud Lailler de l'ANSES, Jean Dupouy-Camet (AVF), Nicole Zucker, sans qui ce travail n'aurait pas pu être réalisé.

\section{CONFLITS D'INTÉRÊTS}

L'auteur ne signale aucun conflit d'intérêt.

\section{BIBLIOGRAPHIE}

- Ancellin R, Berta JL, Dubuisson C. Allergies alimentaires ; connaissances, clinique et prévention. Ministère de l'emploi et de la solidarité-DGS, AFSSA, 2004-01-01.

- Angot JL. Opinion pour une mise en œuvre effective du concept «one world-one health». Bulletin de l'Académie Vétérinaire de France. 2020; 173: 192-195.

- ANSES. Contamination des requins, notamment tigre et bouledogue, par des ciguatoxines : occurrence, méthodes analytiques, cas humains rapportés et éléments d'éthologie . Rapport d'expertise collective. 2015. Disponible à : https://www.anses.fr/ fr/documents/ERCA2013sa01 98Ra.pdf. Consulté le 24/10/2021.

- Arrêté du 8 octobre 2013 relatif aux règles sanitaires applicables aux activités de commerce de détail, d'entreposage et de transport de produits et denrées alimentaires autres que les produits d'origine animale et les denrées alimentaires en contenant. Disponible à : https://www.legifrance gouv.fr/loda/id/JORFTEXT0000 28081402/. Consulté le 26/10/2021.

- Bauduret P, Guignard A. Manuel d'initiation à la mycologie en alimentation animale et d'identification des principales moisissures du genre Aspergillus. Conseil général Saint-Denis-de-la-Réunion. 1988.

- Bulletin Épidémiologique Santé Animale - Alimentation. Numéro spécial surveillance sanitaire des aliments. ANSES - DGAL. 2017 ; 77:
1-96. Disponible à https://be.anses.fr/sites/ default/files/2017-02-20_\%20A NSES\%20BE\%2077\%20SSA_CS6_b d. pdf (Consulté le 24/10/2021). - Charpenay K. Les informations réciproques utiles aux médecins et aux vétérinaires en cas de maladies humaines d'origine animale. Thèse de doctorat vétérinaire Lyon. 2012.

- Guignard A, Lailler R. Rapport d'expertise relatif à la situation sanitaire rencontrée dans le secteur de la restauration scolaire en Nouvelle-Calédonie, entre mars et octobre 2018. Disponible à : https://davar.gouv.nc /sites/default/files/atoms/files/ra pport_expertise_anses_restaur ation_scolaire_en_nouvelle-caled onie.pdf. (Consulté le 24/10/2021)

- Kermarec F, Heyman C, Dor F. Guide pour le diagnostic et la prise en charge des syndromes collectifs inexpliqués Synthèse. Institut de Veille Sanitaire. 2010. Disponible à : https://www.sa ntepubliquefrance.fr/docs/diagnost ic-et-prise-en-charge-des-syndromes-coll ectifs-inexpliques.-synthese. (Consulté le 24/10/2021).

- La Vieille S., Krys S., Aubert P, Belin C. Prévention des intoxications par les phycotoxines marines en France en 2004. Bulletin Épidémiologique AFSSA. $2004 ; 13$ : 3-5

- Quod JP, Turquet J, Patrick Bourdeau, P, Guignard A. La ciguatéra dans les DOM-TOM : aspects épidémiologiques et physiopathologiques. Revue de Médecine Vétérinaire. 1994 ; 170:141-146.
- Quod JP, Prunaux O, Guignard A. Les empoisonnements par poissons tropicaux à l'île de la Réunion : synthèse et perspectives. Revue de Médecine Vétérinaire. 1990; 141 : 1005-1009.

- Règlement (CE) n 2073/2005 de la commission du 15 novembre 2005 concernant les critères microbiologiques applicables aux denrées alimentaires. Disponible à https://eur-lex.eur opa.eu/legal-content/FR/TXT/ PDF/?uri=CELEX:02005R2073. 20140601\&from=ES. (Consulté le 24/10/2021).

- Surveillance des toxi-infections alimentaires collectives (TIAC). Données de la déclaration obligatoire, 2019. Santé Publique France. 2021. Disponible à https://www.santepubliquefra nce.fr/content/download/327767/ 2957326. (Consulté le 24/10/2021).

- Sutra L, Federighi M, Jouve JL. Manuel de bactériologie alimentaire. Paris : éditions Polytechnica ; 1998

- Van Cauteren D, Le Strat Y, Sommen C, Bruyand M, Tourdjman M, Jourdan Da Silva $\mathrm{N}$ et al. Estimation de la morbidité et de la mortalité liées aux infections d'origine alimentaire en France métropolitaine, 2008-2013. Bulletin Épidémiologique Hebdomadaire. $2018 ; 1: 2-10$.

- Watrin M, Erouart S. Investigation d'un syndrome collectif inexpliqué survenu dans un établissement d'enseignement secondaire. Saint-Sauveur-le-Vicomte (50), 6 octobre 2011. Institut de Veille Sanitaire. $2012 ; 1-20$ 


\begin{tabular}{|c|c|c|c|}
\hline $\begin{array}{c}\text { Paramètre } \\
\text { (durée de l'analyse) }\end{array}$ & Signification & Origine & Conduite à tenir \\
\hline $\begin{array}{l}\text { Microorganismes } \\
\text { aérobies } 30^{\circ} \mathrm{C} \text { ou flore } \\
\text { mésophile } \\
\text { (3 jours) }\end{array}$ & $\begin{array}{l}\text { - témoin du niveau général } \\
\text { d'hygiène } \\
\text { - dépend de l'histoire du produit }\end{array}$ & $\begin{array}{l}\text { - rupture de la chaîne du froid } \\
\text { - défaut de fabrication } \\
\text { - mauvaise hygiène générale }\end{array}$ & $\begin{array}{l}\text { - réglage des enceintes froides et chaudes } \\
\text { - respect des durées de chauffe, de refroidissement et de } \\
\text { stockage à température ambiante } \\
\text { - cette flore inclut les Pseudomonas, la flore lactique, et } \\
\text { levures et moisissures }\end{array}$ \\
\hline $\begin{array}{l}\text { Bactéries lactiques } \\
\text { mésophiles } 30^{\circ} \mathrm{C} \\
\text { (3 jours) }\end{array}$ & $\begin{array}{l}\text { - flore d'altération } \\
\text { - ferments lactiques }\end{array}$ & $\begin{array}{l}\text { - rupture de la chaîne du froid } \\
\text { - ajout volontaire dans les } \\
\text { produits de charcuterie } \\
\text { (salaison) } \\
\text { - présence de fromage au lait } \\
\text { cru } \\
\text { - produit sous vide }\end{array}$ & $\begin{array}{l}\text { Apprécier l'importance relative des } 3 \text { flores citées plus haut : } \\
\text { Pseudomonas, la flore lactique, et levures et moisissures. }\end{array}$ \\
\hline $\begin{array}{l}\text { Pseudomonas } 25^{\circ} \mathrm{C} \\
\text { (2 à } 4 \text { jours })\end{array}$ & $\begin{array}{l}\text { - flore d'altération : indicateur de } \\
\text { fraîcheur } \\
\text { - indicateur d'un sous-vide } \\
\text { insuffisant }\end{array}$ & $\begin{array}{l}\text { - viandes } \\
\text { - sol et eaux }\end{array}$ & - contrôler la qualité du sous vide \\
\hline $\begin{array}{l}\text { Enterobacteriaceae ou } \\
\text { entérobactéries } 30^{\circ} \mathrm{C} \\
\text { ( } 1 \text { jour })\end{array}$ & \multirow{4}{*}{$\begin{array}{l}\text { - ces } 4 \text { paramètres constituent des } \\
\text { témoins plus ou moins } \\
\text { spécifiques de contaminations } \\
\text { fécales ou environnementales } \\
\text { - la flore physiologique des } \\
\text { légumes crus est souvent riche en } \\
\text { coliformes } 30^{\circ} \mathrm{C} \text {, et dans une } \\
\text { moindre mesure en coliformes } \\
44^{\circ} \mathrm{C} \\
\text { - par ordre de spécificité fécale } \\
\text { croissante, on note : } \\
\text { entérobactéries, coli } 30, \text { coli } 44, \\
E . \text { coli }\end{array}$} & \multirow{4}{*}{$\begin{array}{l}\text { - en général, lié à un défaut } \\
\text { d'hygiène, ayant entraîné } \\
\text { une contamination d'origine } \\
\text { fécale humaine ou animale } \\
\text { - en l'absence de ce motif, } \\
\text { rechercher une } \\
\text { contamination par des } \\
\text { légumes crus insuffisamment } \\
\text { stérilisés (persil, tomates, par } \\
\text { exemple) }\end{array}$} & \multirow{4}{*}{$\begin{array}{l}\text { - rechercher l'origine dans une contamination fécale probable } \\
\text { - revoir l'hygiène du personnel } \\
\text { - revoir l'hygiène et la désinfection des locaux et du matériel } \\
\text { - revoir le mode de désinfection des légumes } \\
\text { - rechercher la présence de légumes crus } \\
\text { Les } E \text {. coli font partie du groupe des Coli } 44^{\circ} \mathrm{C} \text {, qui eux- } \\
\text { mêmes font partie du groupe des Coli } 30^{\circ} \mathrm{C} \text { et qui eux- } \\
\text { mêmes appartiennent à la famille des entérobactéries. } \\
\text { Il existe donc un rapport quantitatif et qualitatif entre ces } \\
\text { éléments qu'il convient d'interpréter. }\end{array}$} \\
\hline $\begin{array}{c}\text { Coliformes } 30^{\circ} \mathrm{C} \text { ou } \\
\text { « totaux » } \\
(1 \text { jour })\end{array}$ & & & \\
\hline $\begin{array}{l}\text { Coliformes } \\
\text { thermotolérants } 44^{\circ} \mathrm{C} \\
\text { ou « fécaux » } \\
\text { ( } 1 \text { jour })\end{array}$ & & & \\
\hline $\begin{array}{l}\text { Escherichia coli } \beta \text { - } \\
\text { glucuronidase positive } \\
44^{\circ} \mathrm{C} \text { ou } \text { E. coli } \\
\text { (1 jour })\end{array}$ & & & \\
\hline $\begin{array}{c}\text { E. coli présumé } \\
\text { (coquillages) (3 jours) }\end{array}$ & - témoin de contamination fécale & - eaux contaminées & $\begin{array}{l}\text { - retrait de la distribution } \\
\text { - prévenir les services officiels }\end{array}$ \\
\hline $\begin{array}{l}\text { staphylocoques à } \\
\text { coagulase positive } \\
37^{\circ} \mathrm{C} \\
\text { (2 à } 4 \text { jours) }\end{array}$ & $\begin{array}{l}\text { - germe pathogène } \\
\text { (toxine thermostable) } \\
\text { autrefois appelés } \\
\text { «Staphylocoque doré » ou } \\
\text { «Staphylococcus aureus » }\end{array}$ & $\begin{array}{l}\text { - hygiène du personnel : } \\
\text { mains sales, infection (nez, } \\
\text { gorge) } \\
\text { - produits laitiers } \\
\text { - matériel contaminé }\end{array}$ & $\begin{array}{l}\text { - revoir l'hygiène des mains et du matériel } \\
\text { - ne pas maintenir en poste une personne présentant une } \\
\text { plaie suppurée (panaris) ou une infection oropharyngée }\end{array}$ \\
\hline $\begin{array}{l}\text { Bactéries sulfito- } \\
\text { réductrices en } \\
\text { anaérobiose à } 46^{\circ} \mathrm{C} \\
\quad(1 \text { jour })\end{array}$ & $\begin{array}{l}\text { - germes potentiellement } \\
\text { pathogènes }\end{array}$ & $\begin{array}{l}\text { - hygiène de la préparation } \\
\text { - contamination par la terre } \\
\text { - stérilisation insuffisante }\end{array}$ & $\begin{array}{l}\text { - accroître la vigilance sur les matières à risque : sous-vide, } \\
\text { conserves, grosses pièces en anaérobiose } \\
\text { - sur des produits finis, suivre le process en mesurant le } \\
\text { couple durée/température de chaque opération (barème de } \\
\text { stérilisation) }\end{array}$ \\
\hline $\begin{array}{l}\text { Clostridium } \\
\text { perfringens } 37^{\circ} \mathrm{C} \\
\text { (1 à } 5 \text { jours })\end{array}$ & - germe pathogène & \multicolumn{2}{|c|}{$\begin{array}{l}\text { Ces germes appartiennent au groupe des bactéries sulfito-réductrices en anaérobiose. } \\
\text { Même signification. }\end{array}$} \\
\hline $\begin{array}{l}\text { Bacillus cereus } 30^{\circ} \mathrm{C} \\
\quad(2 \text { à } 4 \text { jours })\end{array}$ & - germe pathogène & $\begin{array}{l}\text { - contamination par la terre } \\
\text { - riz, légumineuses, épices } \\
\text { - rupture de la chaîne du froid }\end{array}$ & $\begin{array}{l}\text { - revoir le process de fabrication des produits à base de } \\
\text { pâtes ou de riz : pister les erreurs de refroidissement }\end{array}$ \\
\hline $\begin{array}{l}\text { Levures et moisissures } \\
25^{\circ} \mathrm{C} \\
(5 \text { jours })\end{array}$ & $\begin{array}{l}\text { - flore d'altération } \\
\text { - flore normale des fruits et des } \\
\text { produits de boulangerie (levain) }\end{array}$ & $\begin{array}{l}\text { - air, végétaux, épices } \\
\text { notamment }\end{array}$ & - selon la nature du produit et de la contamination \\
\hline $\begin{array}{r}\text { Salmonella } \\
\text { (2 à } 10 \text { jours) }\end{array}$ & - germe pathogène & \begin{tabular}{|l|} 
- $œ u f s$, ovoproduits \\
- les viandes insuffisamment \\
cuites, préparations de \\
viandes et produits à base de \\
viande crue, etc. \\
- personnel contaminé
\end{tabular} & $\begin{array}{l}\text { - nettoyer et désinfecter les locaux et matériel en cause } \\
\text { - surveiller la qualité des matières premières } \\
\text { - former le personnel aux risques de contaminations } \\
\text { croisées } \\
\text { - surveiller la santé du personnel }\end{array}$ \\
\hline $\begin{array}{c}\text { Listeria } \\
\text { monocytogenes } \\
\text { (2 à } 10 \text { jours }) \\
\text { Le laboratoire } \\
\text { recherche souvent, en } \\
\text { parallèle , les autres } \\
\text { espèces de Listeria }\end{array}$ & - germe pathogène & $\begin{array}{l}\text { - fromage } \\
\text { - charcuterie } \\
\text { - poisson fumé } \\
\text { - chambres froides }\end{array}$ & $\begin{array}{l}\text { - hygiène des locaux } \\
\text { - s'assurer de l'innocuité des produits à longue durée de vie } \\
\text { (plusieurs semaines) }\end{array}$ \\
\hline
\end{tabular}




\begin{tabular}{|c|c|c|c|}
\hline $\begin{array}{c}\text { Vibrio cholerae, } \\
\text { parahaemolyticus, et } \\
\text { autres } \\
\text { (2 à } 10 \text { jours) }\end{array}$ & $\begin{array}{l}\text { - germes pathogènes ou } \\
\text { potentiellement pathogènes }\end{array}$ & - produits de la mer & $\begin{array}{l}\text { - retrait immédiat de la consommation } \\
\text { - prévenir les services officiels }\end{array}$ \\
\hline Enterobacter sakazakii & - germe pathogène & - lait et produits laitiers & \\
\hline Campylobacter & - germe pathogène & $\begin{array}{l}\text { - viande et produits à base de } \\
\text { viande }\end{array}$ & \\
\hline $\begin{array}{c}\text { Entérotoxines } \\
\text { staphylococciques } \\
\text { (7 jours) }\end{array}$ & - toxines thermostables & $\begin{array}{l}\text { - toutes denrées alimentaires } \\
\text { susceptibles d'être } \\
\text { contaminées par des } \\
\text { staphylocoques à coagulase } \\
\text { positive }\end{array}$ & \\
\hline
\end{tabular}

\begin{tabular}{|c|l|l|}
\hline Paramètre & \multicolumn{1}{|c|}{ Signification } & \multicolumn{1}{|c|}{ Limite } \\
\hline $\begin{array}{c}\text { ABVT = Azote } \\
\text { Basique Volatil } \\
\text { Total (1/2 jour) }\end{array}$ & Témoin de fraîcheur. Essentiellement valable pour le poisson. & $\begin{array}{l}\text { Ne pas dépasser 30 mg d'ABVT pour 100 g } \\
\text { de poissons, en général. À moduler selon les } \\
\text { espèces. }\end{array}$ \\
\hline $\begin{array}{c}\text { Histamine (1/2 } \\
\text { jour) }\end{array}$ & $\begin{array}{l}\text { Risque de troubles graves chez le consommateur } \\
\text { Concerne surtout le poisson (thons, sardines, anchois, harengs) }\end{array}$ & $\begin{array}{l}\text { La présence de simples traces peut entraîner des } \\
\text { troubles }\end{array}$ \\
\hline $\begin{array}{c}\text { Phosphatase (1/2 } \\
\text { jour) }\end{array}$ & $\begin{array}{l}\text { Enzyme sensible à la chaleur. Témoin d'une pasteurisation réussie sur les } \\
\text { produits laitiers. Permet d'établir la classification réglementaire du fromage dans } \\
\text { le cadre de l'AM du 30.03.94. }\end{array}$ & $\begin{array}{l}\text { Phosphatase active : lait ni pasteurisé, ni } \\
\text { stérilisé } \\
\text { Phosphatase inactive : lait pasteurisé ou stérilisé }\end{array}$ \\
\hline
\end{tabular}

Tableau 1 : guide d'interprétation des résultats d'analyse microbiologiques (C) Alain Guignard 30/03/2021)

N.B. 1 : Ces tableaux présentent de manière simplifiée les principaux éléments à connaître pour interpréter les résultats. Toutes les situations ne sont pas envisagées. En cas de doute ou de difficultés, contacter le laboratoire prestataire.

N.B. 2 : Les durées habituelles, présentées entre parenthèses, ne tiennent compte que de la durée analytique dans des conditions idéales (commencées le matin en début de semaine, non interrompues par des jours fériés, non retardées par des problèmes techniques).

N.B. 3 : Dans le cadre de l'article 50 de la Loi Egalim, l'article L201-7, modifié par l'ordonnance n²019-1110 du 30.10.2019-art. 2, il est rappelé notamment que: Tout propriétaire ou détenteur de denrées alimentaires ou d'aliments pour animaux soumis aux prescriptions prévues à l'article L. 231-1 informe immédiatement l'autorité administrative désignée par décret lorsqu'il considère ou a des raisons de penser, au regard de tout résultat d'autocontrôle, qu'une denrée alimentaire ou un aliment pour animaux qu'il a importé, produit, transformé, fabriqué ou distribué présente ou est susceptible de présenter un risque pour la santé humaine ou animale. 